\title{
Relationship between Incidence of Cephalosporium Stripe and Yield Loss in Winter Wheat
}

\author{
M. C. Quincke, ${ }^{1,2}$ C. J. Peterson, ${ }^{1,3}$ and C. C. Mundt ${ }^{4}$ \\ ${ }^{1}$ Department of Crop and Soil Science, Oregon State University, Corvallis, OR 97331, USA \\ ${ }^{2}$ Programa Nacional de Cultivos de Secano, Instituto Nacional de Investigación Agropecuaria, INIA La Estanzuela, \\ Ruta $50 \mathrm{~km}$ 11, Colonia 7000, Uruguay \\ ${ }^{3}$ Wheat Research, Limagrain Cereal Seeds, 3515 Richards Lake Road, Fort Collins, CO 80524, USA \\ ${ }^{4}$ Department of Botany and Plant Pathology, Oregon State University, 2082 Cordley Hall, Corvallis, OR 97331-2902, USA
}

Correspondence should be addressed to C. C. Mundt, mundtc@science.oregonstate.edu

Received 12 October 2011; Accepted 12 December 2011

Academic Editor: Juan G. Annone

Copyright (C) 2012 M. C. Quincke et al. This is an open access article distributed under the Creative Commons Attribution License, which permits unrestricted use, distribution, and reproduction in any medium, provided the original work is properly cited.

\begin{abstract}
Cephalosporium stripe (caused by Cephalosporium gramineum) can be a serious disease of winter wheat (Triticum aestivum L.) in the Pacific Northwest of the USA. Effects of Cephalosporium stripe on yield, test weight, protein, and kernel characteristics were examined using 12 winter wheat varieties in field plots inoculated and not inoculated with the pathogen. Averaged over varieties, inoculation decreased yield, test weight, kernel weight, and kernel diameter; grain protein and the standard deviations of kernel weight and kernel diameter were increased by inoculation. Grain yield of the susceptible check was reduced by as much as $41 \%$ with addition of inoculum. The most resistant and the most susceptible varieties performed similarly for yield in the two environments, while varieties with intermediate levels of resistance were sometimes inconsistent. There was a linear relationship between yield and \% whiteheads (sterile heads caused by disease) in one environment and a curvilinear relation in the other.
\end{abstract}

\section{Introduction}

Cephalosporium stripe of wheat is caused by the soil-borne fungal pathogen Cephalosporium gramineum Nisikado and Ikata (syn. Hymenula cerealis Ellis \& Everh.) [1-3]. The fungus has a wide range of hosts, mainly among winter cereals $[4,5]$. Cephalosporium stripe is of economic importance only in winter wheat, however. The disease is an important, limiting factor in many winter wheat production areas [69]. It is widespread throughout the Pacific Northwest of the USA, where wheat growers in erosion-prone areas are particularly affected when early plantings and reduced or no tillage are practiced $[4,10-12]$.

C. gramineum survives between host crops saprophytically as mycelium and conidia in association with host residues on or near the soil surface [13]. Infested crop residue is the primary source of inoculum. Conidia produced in the top layer of soil on crop stubble and released during cool and moist weather conditions during fall and winter are washed down into the root zone to infect the next crop $[14,15]$.
Once inside the roots, the fungus invades the vascular system and has the potential to colonize the entire plant. Successful establishment of C. gramineum inside the host is enhanced by the production of toxic metabolites that block the vascular system, thus preventing normal movement of water and nutrients $[4,11,16]$.

The most typical and recognizable symptom, chlorotic leaf striping, is apparent on the younger, upper leaves during jointing and heading. Severely infected stems are stunted and prematurely ripen, producing a white and usually sterile head, containing sometimes just a few shriveled seeds. It is at this level of infection where the greatest amount of yield loss is observed [3,11, 17-19]. In areas conducive to Cephalosporium stripe (i.e., Kansas and Montana in the USA, and Scotland), up to $80 \%$ yield reduction from a generalized infection on a susceptible cultivar can occur [17, 2023]. Precise information on the impact of Cephalosporium stripe on grain yield for Pacific Northwest conditions is not available. Yield losses caused by this fungus appear to be the product of a combination of reduced seed number and 
reduced seed weight $[17,24]$. Impacts on grain protein, test weight, and end-product quality also may occur [17, 21, 22].

Reducing incidence of Cephalosporium stripe has generally been accomplished by reducing inoculum in the soil via cultural controls such as crop rotation, management of crop residues, altering soil $\mathrm{pH}$ with lime applications, and fertilizer management [14, 25-30]. However, these practices are only partially effective in reducing the incidence and severity of the disease [31] and often are practically or economically unfeasible. Additionally, Cephalosporium stripe cannot be controlled with fungicides. Although variation in the degree of resistance among cultivars has been confirmed, genotypes with complete resistance to $C$. gramineum have not been found $[21,24,32,33]$. However, repeated planting of moderately resistant cultivars has been reported to reduce both the incidence and severity of Cephalosporium stripe over years [34].

The goals of this study were to estimate the magnitude of potential grain yield loss caused by Cephalosporium stripe under Oregon production conditions, its association with changes in test weight and kernel characteristics, and to estimate the level of host plant resistance required to attain minimal yield loss.

\section{Materials and Methods}

2.1. Plant Material. Varieties were included in the experiments based on commercial importance, performance in previous Cephalosporium stripe screening nurseries, and their range in disease response. Ten varieties were evaluated in the Pendleton trials. Stephens (CI 017596), Madsen (PI 511673), and Tubbs (PI 629114) are major cultivars grown in the region. The European cultivar Rossini and two derived breeding lines (OR9800919 and OR9800924, Rossini/Ysatis// Oracle) were included, as these were previously shown to have moderate-to-high levels of disease resistance. Three experimental lines with varying levels of resistance were also included. These originated from crosses between the Rossini-derived lines and adapted Oregon material (OR02F-B-46 (Tubbs//OR9800924/Weatherford), OR02FC-169 (Tubbs//OR9800924/OR9900553) and OR02F-D-27 (OR9800924/Weatherford)). A highly resistant club winter wheat with an alien source of resistance (WA 7437, PI 561033) was included as a resistant check. At Moro, two new releases were added to the previous list of varieties to verify their performance to the disease (Skiles and ORSS-1757). Skiles had previously shown moderate-to-high levels of resistance, while ORSS-1757 (PVP 200500336) was considered moderately susceptible to the disease.

2.2. Field Trials. Field trials were conducted at the Columbia Basin Agricultural Research Center field stations near Pendleton, OR, during the 2005-2006 winter wheat season and in Moro, OR in 2005-2007. Both locations are in semiarid wheat-producing areas of the Columbia Plateau, with mean annual precipitation of $406 \mathrm{~mm}$ in Pendleton and $279 \mathrm{~mm}$ in Moro. These sites are representative of eastern Oregon winter wheat production areas where Cephalosporium stripe is frequent. A randomized complete block design with four replications was used at each location. Treatments consisted of a factorial of two levels of disease (inoculated and noninoculated), with 10 varieties in Pendleton and 12 in Moro; 10 varieties were common to both trials.

Differential disease levels were obtained by sowing autoclaved oat kernels that were previously infested with C. gramineum. Autoclaved oat kernels not infested with the fungus were added to the noninoculated plots. Inoculum was produced following the description by Mathre and Johnston [18] and was added to the seed envelopes before planting at a dose equal in volume to the wheat seed.

Trials were sown into stubble mulch on 12 September 2005 in Pendleton and on 12 September 2006 in Moro. Early September sowing dates increase severity of Cephalosporium stripe at these sites. Each plot was four rows $(1.5 \mathrm{~m}) \times 6.1 \mathrm{~m}$ long. Border plots were included around each trial. A Hege 500 series plot drill (H\&N Manufacturing, Colwich, KS) with deep furrow openers was used to place seed into moist soil. Fertilization and weed control practices were appropriate to commercial winter wheat production at the two sites. Hand weeding was necessary in Pendleton at postanthesis to keep weed pressure low. A spring application of fungicide (Bumper 41.8EC, propiconazole) was applied to avoid infection by Pseudocercosporella herpotrichoides, which can mask symptoms of Cephalosporium stripe. Plots were mowed to approximately $4.5 \mathrm{~m}$ in length postheading and prior to collecting disease data. Plot lengths were recorded before harvest to adjust yield estimations. Trials were harvested during July after maturity and once an adequate level of grain moisture was reached. Entire plots were harvested with a plot combine, adjusted to maximize the retention of shriveled kernels.

Cephalosporium stripe incidence was recorded on a plot basis through visual estimation of the percentage of tillers that were ripening prematurely, and which usually expressed complete or partial reduction of grainfill (whiteheads) [18, $24]$. Evaluation of known check varieties and random examination of lower stems and roots provided confidence that whiteheads were caused predominately by Cephalosporium stripe. Disease notes were taken at each location about 3 wks after heading. Developmental stage of the entries ranged from early milk to early dough at this time. Plant height and physiological maturity were also recorded to study possible association with Cephalosporium stripe resistance.

2.3. Grain Analyses. Harvested grain was carefully cleaned using airflow to remove nongrain contamination. Grain weight per plot was measured with a precision digital scale. A $1 \mathrm{~kg}$ sample was taken from each bag to determine test weight (hectoliter weight), grain protein concentration (\%), and grain moisture content (\%). Test weight and grain moisture were measured with a Grain Analysis Computer (GAC) model 2100b (DICKEY-john Corporation, Auburn, IL). Protein content was measured with an Infratec 1241 Grain Analyzer (Foss, Eden Prairie, MN) with appropriate settings for soft white or hard red winter wheat varieties.

A 300-seed subsample was randomly taken from each bulk and analyzed for kernel weight (mg) and diameter $(\mathrm{mm})$, using a Single-Kernel Characterization System (SKCS) model 4100 (Perten Instruments, Springfield, IL). 
TABLE 1: Analysis of variance for \% whiteheads (square root transformed) and grain parameters for wheat genotypes grown in plots inoculated or not inoculated with Cephalosporium gramineum in Pendleton 2006 and Moro 2007.

\begin{tabular}{|c|c|c|c|c|c|c|c|c|c|}
\hline \multirow{2}{*}{$\begin{array}{l}\text { Environment } \\
\text { Source of variation }\end{array}$} & \multirow{2}{*}{$\mathrm{DF}$} & \multirow{2}{*}{ Whiteheads } & \multirow{2}{*}{ Yield } & \multirow{2}{*}{$\begin{array}{l}\text { Test } \\
\text { weight }\end{array}$} & \multirow{2}{*}{ Protein } & \multicolumn{2}{|c|}{ Kernel weight } & \multicolumn{2}{|c|}{ Kernel diameter } \\
\hline & & & & & & avg & SD & avg & SD \\
\hline \multicolumn{10}{|l|}{ Pendleton, 2006} \\
\hline Block & 3 & 0.31 & $3.12 * *$ & $8.88^{* *}$ & 0.714 & $9.40^{* *}$ & 0.677 & $0.030^{* *}$ & 0.0002 \\
\hline Inoculation & 1 & $113.34^{* *}$ & $21.65^{* *}$ & $212.23^{* *}$ & $5.274^{* *}$ & $77.15^{* *}$ & $42.506^{* *}$ & $0.143^{* *}$ & $0.0590 * *$ \\
\hline Genotype & 9 & $15.08^{* *}$ & $1.21^{* *}$ & $36.27^{* *}$ & 0.546 & $139.08^{* *}$ & $20.803^{* *}$ & $0.332 * *$ & $0.0277^{* *}$ \\
\hline Inoculation $\mathrm{x}$ genotype & 9 & $4.33^{* *}$ & $0.63^{* *}$ & $6.61^{* *}$ & $0.678^{*}$ & $4.52^{* *}$ & $0.781^{*}$ & $0.010^{* *}$ & $0.0017^{* *}$ \\
\hline Error & 57 & 0.20 & 0.20 & 1.34 & 0.320 & 1.61 & 0.330 & 0.003 & 0.0006 \\
\hline CV (\%) & & 22.0 & 9.3 & 1.6 & 5.3 & 3.6 & 5.9 & 2.3 & 4.9 \\
\hline \multicolumn{10}{|l|}{ Moro, 2007} \\
\hline Block & 3 & 0.11 & $0.83^{* *}$ & $10.63^{* *}$ & 0.371 & $25.50^{* *}$ & 0.659 & $0.056^{* *}$ & 0.0011 \\
\hline Inoculation & 1 & $198.27^{* *}$ & $25.06^{* *}$ & $33.36^{* *}$ & 0.004 & $12.80^{*}$ & $5.880^{* *}$ & $0.028^{*}$ & $0.0093 * *$ \\
\hline Genotype & 11 & $7.25^{* *}$ & $1.37^{* *}$ & $30.81^{* *}$ & $2.318^{* *}$ & $96.50^{* *}$ & $8.978^{* *}$ & $0.160^{* *}$ & $0.0109^{* *}$ \\
\hline Inoculation $\mathrm{x}$ genotype & 11 & $2.37^{* *}$ & $0.35^{* *}$ & 1.34 & $1.179^{*}$ & 3.33 & $1.209^{* *}$ & 0.006 & $0.0022^{* *}$ \\
\hline Error & 69 & 0.46 & 0.11 & 0.81 & 0.520 & 2.53 & 0.250 & 0.005 & 0.0005 \\
\hline $\mathrm{CV}(\%)$ & & 16.4 & 9.4 & 1.2 & 8.4 & 4.7 & 5.7 & 2.9 & 4.5 \\
\hline
\end{tabular}

* Significant at the 0.05 probability level.

** Significant at the 0.01 probability level.

For each sample, the SKCS integrated computer software (Perten Instruments, Springfield, IL) provided the means and standard deviations of the 300 individual kernel determinations.

2.4. Statistical Analyses. Statistical analyses were performed with the Statistical Analysis System (SAS) (SAS v9.1, SAS Institute Inc., Cary, NC, USA). Analyses of variance (ANOVA) for disease response, yield, test weight, and kernel related traits were conducted with PROC GLM to determine the level of variation between blocks and to test the significance of both treatment factors (disease and varieties) and their interaction. Type III F statistics were used to test the significance of variance sources. For ANOVA, whitehead percentages were square-root-transformed to meet the assumptions of normality and homogeneity of variance. The significance of the disease treatment on individual varieties was determined with the SLICE option in the LSMEANS statement.

Yield loss for genotypes was estimated as the reduction in grain yield between noninoculated and inoculated plots expressed as percentage relative to the yield in noninoculated plots. Similar calculations were done to estimate loss or change in test weight and kernel traits due to disease.

Pearson correlation coefficients among traits were estimated from genotype least square means using the PROC CORR procedure in SAS, pooling means from inoculated and noninoculated treatments together.

Linear regressions were fitted to estimate the relationship of grain yield loss and test weight loss to the susceptibility of genotypes to Cephalosporium stripe. The level of susceptibility was measured as the difference in whiteheads between inoculated and noninoculated plots. Grain yield loss was calculated for each cultivar as (grain yield inoculated grain yield noninoculated) $* 100 /$ grain yield inoculated, test weight loss was estimated as well and was calculated similarly. Linear and quadratic regressions of yield and test weight loss on disease response differential were fitted using the PROC REG procedure in SAS.

\section{Results}

Averaged over varieties, inoculation significantly decreased yield, test weight, kernel weight, and kernel diameter; grain protein at Pendleton and the standard deviations of kernel weight and kernel diameter at both locations were significantly increased by inoculation (Table 1). Main effects were significant for all variables in both experiments, with the exception of grain protein, which showed no significant effect of genotypes in either location (Table 1). However, all variables showed a significant interaction $(P=0.05)$ between the inoculation treatment and genotype in Pendleton. For the Moro trial the interaction term was also significant $(P=$ 0.05 ) for most of the variables, with the exceptions of test weight, kernel weight, and kernel diameter.

Cephalosporium stripe occurred in noninoculated plots of both trials, but more so at Moro than at Pendleton (Tables 2 and 4). Nonetheless, the mean disease scores (\% whiteheads) for genotypes differed significantly $(P<0.01)$ under inoculated versus noninoculated conditions for all varieties, with the exception of WA 7437 and OR9800924 in Pendleton (Table 2) and WA 7437 in Moro (Table 4). Stephens, a highly susceptible cultivar, showed the biggest difference in percentage whiteheads between inoculated and noninoculated plots (41.3 and $42.5 \%$ for Pendleton and Moro, resp.) and the greatest yield loss (32.0 and $41.2 \%$, resp.). 
TABle 2: Percent whiteheads, grain yield, test weight, and grain protein of 10 wheat genotypes noninoculated (U) and inoculated (I) with Cephalosporium gramineum in field plots in Pendleton, Oregon, 2006.

\begin{tabular}{|c|c|c|c|c|c|c|c|c|c|c|c|c|}
\hline & \multicolumn{3}{|c|}{ Whiteheads (\%) } & \multicolumn{3}{|c|}{ Grain yield $\left(\mathrm{tha}^{-1}\right)$} & \multicolumn{3}{|c|}{ Test weight $\left(\mathrm{kg} \mathrm{hl}^{-1}\right)$} & \multicolumn{3}{|c|}{ Grain protein (\%) } \\
\hline & $\mathrm{U}$ & I & Change $^{a}$ & $\mathrm{U}$ & I & $\begin{array}{l}\text { Loss } \\
(\%)^{\mathrm{b}}\end{array}$ & $\mathrm{U}$ & I & Loss & $\mathrm{U}$ & I & Change \\
\hline Stephens & 5.8 & 47.0 & $41.3^{* *}$ & 5.35 & 3.64 & $32.0^{* *}$ & 77.15 & 71.73 & $5.43^{* *}$ & 10.31 & 11.46 & $1.15^{* *}$ \\
\hline Madsen & 0.5 & 13.3 & $12.8^{* *}$ & 5.58 & 4.20 & $24.8^{* *}$ & 78.05 & 73.68 & $4.38^{* *}$ & 10.40 & 10.97 & 0.57 \\
\hline Tubbs & 2.9 & 35.8 & $32.9^{* *}$ & 5.66 & 4.03 & $28.9^{* *}$ & 76.95 & 72.10 & $4.85^{* *}$ & 10.17 & 10.92 & 0.75 \\
\hline OR9800919 & 0.6 & 9.0 & $8.4^{* *}$ & 5.77 & 4.95 & $14.2^{*}$ & 74.28 & 71.10 & $3.18^{* *}$ & 10.47 & 10.88 & 0.42 \\
\hline OR9800924 & 0.2 & 1.1 & 0.9 & 4.90 & 4.82 & 1.7 & 75.80 & 74.38 & 1.43 & 10.74 & 10.92 & 0.18 \\
\hline Rossini & 1.1 & 17.5 & $16.4^{* *}$ & 5.91 & 4.50 & $23.8^{* *}$ & 77.63 & 73.93 & $3.70^{* *}$ & 10.02 & 10.63 & 0.61 \\
\hline OR02F-B-46 & 0.4 & 4.8 & $4.3^{* *}$ & 5.71 & 4.54 & $20.6^{* *}$ & 72.83 & 70.30 & $2.53^{* *}$ & 10.31 & 10.69 & 0.38 \\
\hline OR02F-C-169 & 0.5 & 11.8 & $11.2^{* *}$ & 4.70 & 3.38 & $28.1^{* *}$ & 78.30 & 72.88 & $5.43^{* *}$ & 10.29 & 11.59 & $1.31^{* *}$ \\
\hline OR02F-D-27 & 0.1 & 5.0 & $4.9^{* *}$ & 5.01 & 4.59 & 8.3 & 71.78 & 70.33 & 1.45 & 9.86 & 10.47 & 0.62 \\
\hline WA 7437 & 0.0 & 0.0 & 0.0 & 4.72 & 4.27 & 9.5 & 78.08 & 77.85 & 0.23 & 11.32 & 10.49 & $-0.83^{*}$ \\
\hline LSD (0.05) & 3.7 & 3.7 & & 0.63 & 0.63 & & 1.64 & 1.64 & & 0.80 & 0.80 & \\
\hline
\end{tabular}

${ }^{*}$ Significant at the 0.05 probability level. ${ }^{* *}$ Significant at the 0.01 probability level.

a Significance is based on percent whiteheads square root transformed.

${ }^{\mathrm{b}}$ Grain yield loss $(\%)=($ noninoculated - inoculated $) /$ noninoculated $* 100$.

TABLE 3: Kernel parameters of 10 wheat genotypes grown noninoculated (U) and inoculated (I) with Cephalosporium gramineum in field plots in Pendleton, Oregon, 2006.

\begin{tabular}{lccccccccccccccc}
\hline & \multicolumn{3}{c}{ Kernel weight avg $(\mathrm{mg})$} & \multicolumn{3}{c}{ Kernel weight SD } & \multicolumn{4}{c}{ Kernel diameter avg (mm) } & \multicolumn{3}{c}{ Kernel diameter SD } \\
& $\mathrm{U}$ & $\mathrm{I}$ & Change $^{\mathrm{a}}$ & $\mathrm{U}$ & $\mathrm{I}$ & Change & $\mathrm{U}$ & $\mathrm{I}$ & Change & U & $\mathrm{I}$ & Change \\
\hline Stephens & 40.59 & 37.42 & $-3.17^{* *}$ & 10.93 & 13.41 & $2.48^{* *}$ & 2.784 & 2.650 & $-0.135^{* *}$ & 0.582 & 0.667 & $0.085^{* *}$ \\
Madsen & 33.18 & 30.96 & $-2.22^{*}$ & 8.62 & 9.94 & $1.32^{* *}$ & 2.437 & 2.355 & -0.082 & 0.444 & 0.509 & $0.065^{* *}$ \\
Tubbs & 37.88 & 36.36 & -1.51 & 10.28 & 12.49 & $2.21^{* *}$ & 2.673 & 2.594 & -0.078 & 0.525 & 0.619 & $0.094^{* *}$ \\
OR9800919 & 38.67 & 36.63 & $-2.05^{*}$ & 8.89 & 9.97 & $1.08^{* *}$ & 2.791 & 2.704 & $-0.087^{*}$ & 0.530 & 0.560 & 0.031 \\
OR9800924 & 37.28 & 35.65 & -1.63 & 8.77 & 9.52 & 0.75 & 2.704 & 2.641 & -0.063 & 0.496 & 0.516 & 0.020 \\
Rossini & 44.08 & 42.74 & -1.34 & 9.74 & 11.28 & $1.54^{* *}$ & 2.991 & 2.970 & -0.021 & 0.517 & 0.588 & $0.071^{* *}$ \\
OR02F-B-46 & 34.04 & 31.38 & $-2.66^{* *}$ & 8.90 & 10.61 & $1.71^{* *}$ & 2.523 & 2.390 & $-0.134^{* *}$ & 0.474 & 0.514 & $0.040^{*}$ \\
OR02F-C-169 & 35.39 & 30.34 & $-5.05^{* *}$ & 9.51 & 11.18 & $1.67^{* *}$ & 2.576 & 2.337 & $-0.239^{* *}$ & 0.485 & 0.572 & $0.088^{* *}$ \\
OR02F-D-27 & 30.64 & 31.07 & 0.42 & 7.59 & 8.99 & $1.40^{* *}$ & 2.382 & 2.388 & 0.006 & 0.460 & 0.487 & 0.027 \\
WA 7437 & 30.62 & 30.19 & -0.43 & 6.21 & 6.61 & 0.40 & 2.359 & 2.346 & -0.013 & 0.405 & 0.426 & 0.022 \\
LSD (0.05) & 1.80 & 1.80 & & 0.81 & 0.81 & & 0.078 & 0.078 & & & 0.035 & 0.035 \\
\hline
\end{tabular}

${ }^{*}$ Significant at the 0.05 probability level. ${ }^{* *}$ Significant at the 0.01 probability level.

${ }^{\mathrm{a}}$ Change $=($ inoculated - noninoculated $)$.

Genotypes with significant grain yield loss also had significant reductions in test weight in Pendleton. The reduction in test weight ranged from 0.23 to $5.43 \mathrm{~kg} \mathrm{hl}^{-1}$. SD of kernel weight and kernel diameter also were affected by increased disease levels. The same eight genotypes that showed an increase in whitehead scores had a significant increase in kernel weight SD, and six of these genotypes also showed an increase in kernel diameter SD, reflecting an increase in kernel size variability due to higher disease incidence (Tables 3 and 5). Differences in test weight among varieties at Moro were small and nonsignificant for many genotypes. None of the other variables studied at this location presented consistent changes among inoculated and noninoculated treatments. Significant changes were observed but were always genotype dependant.

There was a negative correlation of disease scores with grain yield, with $r$-values of -0.62 at Pendleton and -0.81 at Moro (Table 6). Similar correlations, but lower in magnitude, were observed between disease and test weight, with $r=$ -0.52 at Pendleton and $r=-0.44$ at Moro. Overall, grain yield was independent of test weight, with a nonsignificant correlation $(P>0.05)$. In Pendleton 2006, Cephalosporium stripe response was positively correlated $(P<0.001)$ with kernel weight SD and kernel diameter SD, as would be expected from differences observed among genotypes at contrasting disease levels. These correlations were not significant 
TABLE 4: Percent whiteheads, grain yield, test weight and grain protein of 12 wheat genotypes noninoculated (U) and inoculated (I) with Cephalosporium gramineum in field plots in Moro, Oregon, 2007.

\begin{tabular}{|c|c|c|c|c|c|c|c|c|c|c|c|c|}
\hline & \multicolumn{3}{|c|}{ Whiteheads (\%) } & \multicolumn{3}{|c|}{ Grain yield $\left(\mathrm{t} \mathrm{ha}^{-1}\right)$} & \multicolumn{3}{|c|}{ Test weight $\left(\mathrm{kg} \mathrm{hl}^{-1}\right)$} & \multicolumn{3}{|c|}{ Grain protein $(\%)$} \\
\hline & $\mathrm{U}$ & I & Change $^{\mathrm{a}}$ & $\mathrm{U}$ & I & $\begin{array}{l}\text { Loss } \\
(\%)^{\mathrm{b}}\end{array}$ & $\mathrm{U}$ & I & Loss & $\mathrm{U}$ & I & Change \\
\hline Stephens & 10.0 & 52.5 & $42.5^{* *}$ & 4.26 & 2.51 & $41.2^{* *}$ & 77.62 & 74.81 & $2.81^{* *}$ & 9.03 & 8.70 & -0.33 \\
\hline Madsen & 6.8 & 18.3 & $11.5^{* *}$ & 4.10 & 3.57 & $13.1^{*}$ & 78.17 & 77.33 & 0.84 & 9.88 & 8.25 & $-1.63^{* *}$ \\
\hline Tubbs & 11.8 & 45.0 & $33.3^{* *}$ & 3.82 & 2.88 & $24.6^{* *}$ & 76.03 & 74.16 & $1.87^{* *}$ & 9.00 & 8.75 & -0.25 \\
\hline OR9800919 & 2.8 & 31.8 & $29.0 * *$ & 5.01 & 3.51 & $30.0^{* *}$ & 74.19 & 72.45 & $1.74^{* *}$ & 7.43 & 8.15 & 0.73 \\
\hline OR9800924 & 4.3 & 26.3 & $22.0 * *$ & 4.44 & 3.41 & $23.2^{* *}$ & 74.87 & 74.68 & 0.19 & 7.80 & 9.15 & $1.35^{* *}$ \\
\hline Rossini & 1.5 & 14.5 & $13.0^{* *}$ & 4.21 & 3.58 & $14.8^{*}$ & 77.94 & 76.07 & $1.87^{* *}$ & 8.83 & 8.18 & -0.65 \\
\hline OR02F-B-46 & 22.5 & 44.3 & $21.8^{* *}$ & 3.41 & 2.71 & $20.7^{* *}$ & 72.71 & 72.77 & -0.06 & 8.80 & 9.23 & 0.42 \\
\hline OR02F-C-169 & 7.8 & 42.5 & $34.8^{* *}$ & 3.80 & 2.43 & $36.0^{* *}$ & 77.97 & 76.87 & 1.10 & 9.85 & 9.30 & -0.55 \\
\hline OR02F-D-27 & 14.0 & 34.3 & $20.3^{* *}$ & 4.12 & 2.81 & $31.6^{* *}$ & 73.58 & 73.19 & 0.39 & 7.68 & 8.15 & 0.48 \\
\hline WA 7437 & 7.5 & 12.8 & 5.3 & 3.15 & 2.76 & 12.3 & 76.94 & 76.00 & 0.94 & 8.53 & 8.50 & -0.03 \\
\hline Skiles & 6.8 & 35.0 & $28.3^{* *}$ & 4.65 & 3.41 & $26.6^{* *}$ & 79.43 & 78.00 & $1.42^{*}$ & 8.38 & 8.80 & 0.43 \\
\hline ORSS-1757 & 5.0 & 37.5 & $32.5^{* *}$ & 4.07 & 3.10 & $23.6^{* *}$ & 77.91 & 76.87 & 1.03 & 7.93 & 7.80 & -0.13 \\
\hline LSD (0.05) & 8.6 & 8.6 & & 0.47 & 0.47 & & 1.27 & 1.27 & & 1.02 & 1.02 & \\
\hline
\end{tabular}

* Significant at the 0.05 probability level. ${ }^{*}$ S Significant at the 0.01 probability level.

a Significance is based on percent whiteheads square root-transformed.

${ }^{\mathrm{b}}$ Grain yield loss $(\%)=($ noninoculated - inoculated $) /$ noninoculated ${ }^{*} 100$.

TABLE 5: Kernel parameters of 12 wheat genotypes grown noninoculated (U) and inoculated (I) with Cephalosporium gramineum in field plots in Moro, Oregon, 2007.

\begin{tabular}{lcccccccccccccc}
\hline & \multicolumn{3}{c}{ Kernel weight avg $(\mathrm{mg})$} & \multicolumn{3}{c}{ Kernel weight SD } & \multicolumn{3}{c}{ Kernel diameter avg (mm) } & \multicolumn{3}{c}{ Kernel diameter SD } \\
& $\mathrm{U}$ & $\mathrm{I}$ & Change & $\mathrm{U}$ & $\mathrm{I}$ & Change & $\mathrm{U}$ & $\mathrm{I}$ & Change & $\mathrm{U}$ & $\mathrm{I}$ & Change \\
\hline Stephens & 37.34 & 35.22 & -2.12 & 8.42 & 10.77 & $2.35^{* *}$ & 2.628 & 2.534 & -0.094 & 0.473 & 0.563 & $0.090^{* *}$ \\
Madsen & 31.26 & 31.31 & 0.05 & 7.63 & 8.17 & 0.53 & 2.396 & 2.441 & 0.045 & 0.420 & 0.468 & $0.048^{* *}$ \\
Tubbs & 33.75 & 32.76 & -0.99 & 8.94 & 9.90 & $0.96^{* *}$ & 2.471 & 2.413 & -0.058 & 0.463 & 0.500 & $0.037^{*}$ \\
OR9800919 & 37.06 & 33.30 & $-3.75^{* *}$ & 7.80 & 8.07 & 0.27 & 2.610 & 2.458 & $-0.152^{* *}$ & 0.475 & 0.473 & -0.002 \\
OR9800924 & 34.61 & 33.77 & -0.84 & 8.69 & 8.10 & -0.58 & 2.555 & 2.508 & -0.047 & 0.501 & 0.474 & -0.027 \\
Rossini & 41.39 & 41.15 & -0.24 & 10.67 & 11.68 & $1.00^{* *}$ & 2.811 & 2.784 & -0.027 & 0.558 & 0.582 & 0.024 \\
OR02F-B-46 & 30.55 & 32.01 & 1.46 & 8.05 & 8.86 & $0.80^{*}$ & 2.360 & 2.397 & 0.037 & 0.437 & 0.468 & $0.032^{*}$ \\
OR02F-C-169 & 33.17 & 33.04 & -0.13 & 8.69 & 9.14 & 0.46 & 2.477 & 2.465 & -0.012 & 0.466 & 0.496 & 0.030 \\
OR02F-D-27 & 32.43 & 32.49 & 0.06 & 8.40 & 8.53 & 0.13 & 2.425 & 2.429 & 0.004 & 0.471 & 0.497 & 0.026 \\
WA 7437 & 27.36 & 26.97 & -0.39 & 7.12 & 6.66 & -0.46 & 2.207 & 2.173 & -0.034 & 0.450 & 0.422 & -0.028 \\
Skiles & 37.43 & 36.08 & -1.35 & 9.15 & 9.04 & -0.11 & 2.538 & 2.482 & -0.056 & 0.526 & 0.513 & -0.013 \\
ORSS-1757 & 34.99 & 34.48 & -0.52 & 8.62 & 9.19 & 0.58 & 2.517 & 2.499 & -0.018 & 0.483 & 0.503 & 0.019 \\
LSD (0.05) & 2.24 & 2.24 & & 0.71 & 0.71 & & 0.100 & 0.100 & & 0.032 & 0.032 & \\
\hline
\end{tabular}

* Significant at the 0.05 probability level. ${ }^{* *}$ Significant at the 0.01 probability level.

${ }^{\text {a Change }}=$ (inoculated - noninoculated $)$.

at Moro. There was no significant correlation between disease and mean kernel weight or mean kernel diameter at either location.

Regressions were fitted to estimate \% grain yield and test weight loss as a function of increasing susceptibility to Cephalosporium stripe. The response of grain yield to whiteheads difference between inoculated and noninoculated plots in Pendleton followed a polynomial regression that included a quadratic term (Figure 1). The regression model was highly significant $(P<0.001)$ with a coefficient of determination $\left(r^{2}\right)$ of 0.76 . The intercept was estimated to be $6.44 \%$, but was not significant $(P=0.11)$. In Moro, the data were best represented with a simple linear regression with coefficient of determination $\left(r^{2}\right)$ of 0.74 (Figure 1). The intercept $(7.49 \%)$ was significant at $P=0.06$.

The relationship between whiteheads and reductions in test weight was nonlinear for both locations. The best fit was a polynomial regression with significant quadratic terms $(P<0.05)$ (Figure 2). The intercept was significant for Moro $(P<0.05)$; however, it was not statistically different from zero at Pendleton $(P=0.19)$. The linear coefficients were highly significant $(P<0.01)$ for Pendleton but not for 
TABLE 6: Pearson correlation coefficients among Cephalosporium stripe rating, grain yield, test weight, and several kernel traits of 10 varieties tested in Pendleton 2006 (below diagonal) and 12 varieties tested in Moro 2007 (above diagonal) under inoculated and noninoculated conditions.

\begin{tabular}{|c|c|c|c|c|c|c|c|c|c|}
\hline & Whiteheads & $\begin{array}{c}\text { Whiteheads } \\
\text { SQRT }\end{array}$ & $\begin{array}{l}\text { Grain } \\
\text { yield }\end{array}$ & $\begin{array}{c}\text { Test } \\
\text { weight }\end{array}$ & $\begin{array}{l}\text { Grain } \\
\text { protein }\end{array}$ & $\begin{array}{l}\text { Kernel weight } \\
\text { (avg) }\end{array}$ & $\begin{array}{l}\text { Kernel weight } \\
\text { (SD) }\end{array}$ & $\begin{array}{l}\text { Kernel diameter } \\
\text { (avg) }\end{array}$ & $\begin{array}{l}\text { Kernel diameter } \\
\text { (SD) }\end{array}$ \\
\hline \multirow{2}{*}{ Whiteheads } & - & 0.986 & -0.809 & -0.435 & 0.134 & -0.155 & 0.290 & -0.190 & 0.217 \\
\hline & & $* * *$ & $* * *$ & * & ns & ns & ns & ns & ns \\
\hline \multirow{2}{*}{$\begin{array}{l}\text { Whiteheads } \\
\text { SQRT }\end{array}$} & 0.952 & - & -0.820 & -0.447 & 0.142 & -0.217 & 0.228 & -0.249 & 0.145 \\
\hline & $* * *$ & & $* * *$ & * & ns & ns & ns & ns & ns \\
\hline \multirow{2}{*}{ Grain yield } & -0.626 & -0.618 & - & 0.304 & -0.271 & 0.461 & -0.096 & 0.464 & -0.011 \\
\hline & $* *$ & $* *$ & & ns & ns & * & ns & $*$ & ns \\
\hline \multirow{2}{*}{ Test weight } & -0.433 & -0.517 & 0.389 & - & 0.273 & 0.263 & 0.093 & 0.210 & 0.140 \\
\hline & + & $*$ & + & & ns & ns & ns & ns & ns \\
\hline \multirow{2}{*}{ Grain protein } & 0.540 & 0.526 & -0.749 & -0.262 & - & -0.161 & -0.001 & -0.141 & -0.235 \\
\hline & * & * & $* * *$ & ns & & ns & ns & ns & ns \\
\hline \multirow{2}{*}{$\begin{array}{l}\text { Kernel weight } \\
\text { (avg) }\end{array}$} & 0.176 & 0.211 & 0.419 & 0.229 & -0.266 & - & 0.747 & 0.971 & 0.794 \\
\hline & ns & ns & + & ns & ns & & $* * *$ & $* * *$ & $* * *$ \\
\hline \multirow{2}{*}{$\begin{array}{l}\text { Kernel weight } \\
\text { (SD) }\end{array}$} & 0.793 & 0.881 & -0.378 & -0.413 & 0.332 & 0.442 & - & 0.730 & 0.910 \\
\hline & $* * *$ & $* * *$ & ns & + & ns & $*$ & & $* * *$ & $* * *$ \\
\hline \multirow{2}{*}{$\begin{array}{l}\text { Kernel diam. } \\
\text { (avg) }\end{array}$} & 0.123 & 0.161 & 0.428 & 0.183 & -0.262 & 0.988 & 0.382 & - & 0.751 \\
\hline & ns & ns & + & $\mathrm{ns}$ & ns & $* * *$ & + & & $* * *$ \\
\hline \multirow{2}{*}{$\begin{array}{l}\text { Kernel diam. } \\
\text { (SD) }\end{array}$} & 0.812 & 0.879 & -0.376 & -0.429 & 0.367 & 0.520 & 0.946 & 0.486 & - \\
\hline & $* * *$ & $* * *$ & ns & + & ns & $*$ & $* * *$ & $*$ & \\
\hline
\end{tabular}

${ }^{+}$Significant at the 0.10 probability level. ${ }^{*}$ Significant at the 0.05 probability level. ${ }^{* *}$ Significant at the 0.01 probability level. ${ }^{* * *}$ Significant at the 0.001 probability level.

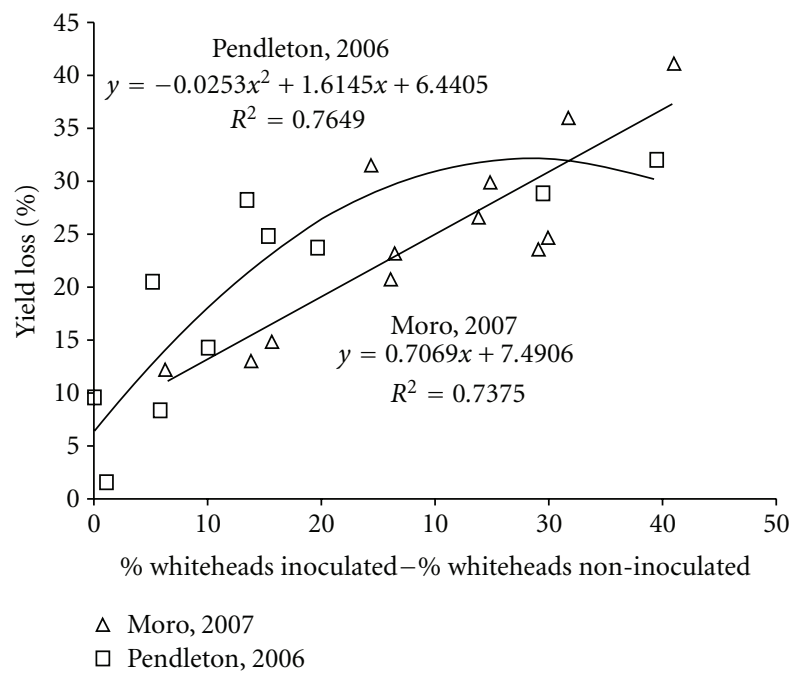

FIGURE 1: Yield loss caused by inoculation of wheat genotypes with Cephalosporium gramineum in Pendleton 2006 (10 wheat genotypes) and Moro 2007 (12 wheat genotypes).

the Moro trial $(P=0.10)$. Coefficients of determination were 0.80 and 0.53 for Pendleton and Moro, respectively.

\section{Discussion}

The general objective of yield loss studies is to provide quantitative estimates regarding effect of disease on its host crop

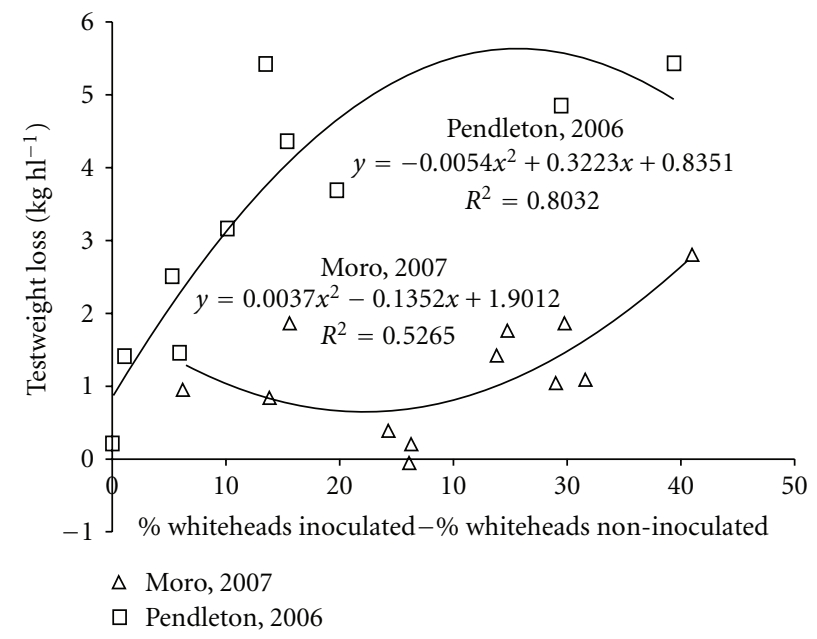

FIGURE 2: Reduction of grain test weight caused by inoculation of wheat genotypes with Cephalosporium gramineum in Pendleton 2006 (10 wheat genotypes) and Moro 2007 (12 wheat genotypes.

[35]. In many host-pathogen systems, the assessment of crop damage is done using comparisons with a fungicide-protected control $[36,37]$. Trials often include artificial inoculation of the pathogen to ensure high and uniform disease pressure. For Cephalosporium stripe, such studies are limited to treatments with artificial inoculation only $[17,20,22$, 38 ] as no fungicides are yet available for the control of 
C. gramineum. Because low levels of whiteheads occurred in noninoculated plots in Pendleton, and even higher levels occurred in Moro, we evaluated yield loss based on differences in whiteheads between inoculated and noninoculated plots.

Despite major differences in rainfall, soil fertility, and environmental stress, susceptible and resistant varieties performed similarly at both Pendleton and Moro. The range of differences in whiteheads between inoculated and noninoculated plots was also similar among locations, with a maximum increase of $40 \%$. Lines with intermediate levels of Cephalosporium stripe showed more variability between locations, however. OR9800924 performed similarly to WA 7437 (resistant check), in Pendleton. In Moro, however, the same variety had a mean $22.0 \%$ increase in whiteheads and $23.2 \%$ grain yield loss under inoculation. This is not surprising, as significant year $\times$ treatment interaction has been reported for Cephalosporium stripe response and associated yield losses by Bockus et al. [20]. Roberts and Allan [39] found no significant genotypic differences for response to $C$. gramineum among 20 varieties in one trial, but important differences among the same set of varieties were found in two other experiments. In our study, some varieties performed differently at each location. Madsen, for example, which is considered to have acceptable levels of field resistance, showed at Pendleton $12.8 \%$ whiteheads difference with a mean $24.8 \%$ yield loss, close to the level of yield reduction exhibited by the susceptible cultivars Stephens and Tubbs. In Moro, however, with similar whiteheads difference (11.5\%), yield loss was only $13.0 \%$ and was similar to the reduction observed for the resistant check (WA 7437). All Rossini-derived genotypes, selected in Pendleton, showed less whiteheads under inoculation than their resistant parent in the Pendleton trial, with yield losses ranging from $1.7 \%$ to $28.1 \%$. In Moro, however, these lines had higher whiteheads differences than Rossini and yield losses between 21.0 and $36.0 \%$. This indicates that selection for resistance to Cephalosporium stripe should be performed under inoculation in both environments for best results.

Regressions of grain yield loss on whitehead change were similar for both environments, although fitted models were not the same. At Pendleton, a quadratic polynomial provided the best fit, while at Moro the relationship was linear. Intercepts of the two models indicated similar yield loss at zero whitehead change (6.44 and $7.49 \%$ at Pendleton and Moro, resp.), though statistical support for the intercepts was not high in either case $(P=0.06$ and $P=0.11$ at Pendleton and Moro, resp.). It is noticeable that the intercepts were positive, indicating that even for highly resistant varieties some level of yield loss may occur under high disease pressure. As an example, the highly resistant selection WA 7437 showed around 10\% grain yield loss in both environments, yet not significant, with $5 \%$ whiteheads or less. Thus, infection by C. gramineum probably induces sufficient damage to cause yield loss even in absence of whiteheads. In fact, leaf symptoms are commonly seen on infected plants in absence of whiteheads. Another possibility is that resistance mechanisms induced by the pathogen result in physiological "costs" to the host $[40,41]$. "Cost of resistance" has been observed for resistance genes in several host-pathogen systems [37, 42]. When a plant is attacked by a pathogen it induces defense mechanisms that are energy demanding, implying an extra cost for the plant. However, there are no reports as to whether resistance to Cephalosporium stripe involves such a defense mechanism.

At-low-to intermediate disease levels, the relationship between disease and yield loss was linear for both environments. Regression coefficients for Pendleton (0.6) and Moro (0.7) suggest that for each additional unit increase in disease pressure, there is a loss of 0.6 to $0.7 \%$ in grain yield (Figure 1). Maximum yield losses estimated by the regressions were around 30 to $35 \%$ for Pendleton and Moro, though higher yield losses are certainly possible under more severe disease pressure. Bockus et al. [20] reported yield loss to Cephalosporium stripe ranged from 26 to $65 \%$ on a single susceptible cultivar, depending on the year. Earlier, Richardson and Rennie [23] and Johnston and Mathre [17] had reported estimates of potential yield loss on individual plants of up to 70 and $78 \%$ respectively.

Analysis of test weight is often included in yield-loss studies to evaluate the effect of disease on grain quality, which can be an important component of the monetary value of the crop. The inclusion of a quadratic effect increased the overall fit of the regressions however, shapes of the curves differed between the two sites. For Pendleton, the function was parabolic while, for Moro, there was a hyperbolic relationship between loss of test weight and whitehead increase. Maximum reduction in test weight was recorded for Stephens and OR02F-C-169 at Pendleton and was $5.43 \mathrm{~kg} \mathrm{hl}^{-1}$.

Test weight loss increased linearly at a rate of $0.32 \mathrm{~kg} \mathrm{hl}^{-1}$ for each unit increase in whiteheads in Pendleton. As whiteheads increased to 15 to $20 \%$, the slope decreased, meaning the rate of change in test weight was less at higher disease levels. In contrast, results from Moro indicated that test weight losses were not substantial until more than $25 \%$ whiteheads change was observed. The maximum loss observed at Moro was about half of that observed in Pendleton. In studies on take-all, which is another soil-borne pathogen that affects wheat and also produces whiteheads, test weight was usually inversely related to disease severity and responded to take-all intensity similarly to grain yield [38].

In Pendleton, Cephalosporium stripe not only affected grain yield and test weight, but also had a significant impact on uniformity of kernel size and weight. Morton and Mathre [22], investigating the physiological effects of C. gramineum on winter wheat, determined that pathogenesis was most damaging after anthesis during the grain filling period. The disease had little impact on the number of seeds per spike, but had large impact on kernel weight. Richardson and Rennie [23] also attributed grain yield losses to the effects of the pathogen that occur later in the life of plants, meaning grain filling. Johnston and Mathre [17] reported that decreased yield of infected plants was related to both decreased weight and number of seeds formed per head. In the Moro trial, although test weight decreased, kernel attributes did not change in relation to increasing disease. Perhaps the disease contributed to subtle changes in kernel conformation, or shape, unrelated to weight or size, that 
impacted test weight. The significant yield losses at Moro, without corresponding changes in kernel weight, suggest the disease either reduced tillering or kernel number, as was suggested by Johnston and Mathre [17].

The role and impact of plant pathogens are not static, but change in relation to varieties, environments, management, and cropping systems. Understanding potential damage, risk, and vulnerability from pathogens is important to prioritizing breeding objectives and allocating resources to crossing, selection, and screening of germplasm. It also has direct impact on release decisions, in that new cultivars should have low risk of yield loss from major diseases that occur in the target region. For producers, risk of losses from pathogens are important considerations in many management decisions, including choice of tillage practices, planting date, crop rotations, and choice of varieties. For example, potential yield gains from early fall seeding dates can be far outweighed by increased risk of damage from soil diseases.

Cephalosporium stripe is known to cause significant damage to wheat grown in the Pacific Northwest. Economic damage has been erratic, often inconsistent within fields, and generally reduced by avoiding early plantings. Cephalosporium stripe often is lumped into the category of "chronic diseases," for which modest resources have been allocated for prevention and breeding for resistance. In this study, there was evidence for yield reduction in presence of the disease before whitehead symptoms were significant. Yield losses of nearly $50 \%$ were found in the most susceptible varieties. Intermediate levels of resistance were shown to be valuable in reducing economic damage from the pathogen. Varieties with intermediate resistances should be sufficient for most production situations, especially as the disease is generally not highly aggressive. However, higher levels of resistance, as observed in WA 7437, are needed to avoid losses with high inoculum levels and favorable environmental conditions.

\section{Acknowledgments}

The authors thank Erling Jacobsen, Karl Rhinhart, Kathryn Sackett, and LaRae Wallace for their contributions to the establishment and maintenance of the field plots.

\section{References}

[1] G. W. Bruehl, "Cephalosporium stripe disease of wheat in Washington," Phytopathology, vol. 46, pp. 178-180, 1956.

[2] J. B. Ellis and B. M. Everhart, "New species of fungi from various localities," Proceedings of the Academy of Natural Sciences of Philadelphia, vol. 46, pp. 322-386, 894.

[3] Y. Nisikado, H. Matsumoto, and K. Yamuti, "Studies on a new Cephalosporium, which causes the stripe disease of wheat," Bericht des Ohara Instituts fur Landwirtschaftliche Forschungen, vol. 6, pp. 275-306, 1934.

[4] G. W. Bruehl, "Cephalosporium stripe disease of wheat," Phytopathology, vol. 47, pp. 641-649, 1957.

[5] W. G. Willis and O. D. Shively, "Cephalosporium stripe of winter wheat and barley in Kansas," Plant Disease Reporter, vol. 58, pp. 566-567, 1974.

[6] E. G. Gray and M. Noble, "Cephalosporium stripe in cereals in Scotland," FAO Plant Protection Bulletin, vol. 8, p. 46, 1960.
[7] D. L. Hawksworth and J. M. Waller, "Hymenula cerealis," Descriptions of Fungi and Bacteria, CAB International, UK, Sheet 501, 1976.

[8] K. Kobayashi and T. Ui, "Phytotoxicity and antimicrobial activity of graminin A, produced by Cephalosporium gramineum, the causal agent of Cephalosporium stripe disease of wheat," Physiological Plant Pathology, vol. 14, no. 1, pp. 129$133,1979$.

[9] D. B. Slope and R. Bardner, "Cephalosporium stripe of wheat and root damage by insects," Plant Pathology, vol. 14, pp. 187$187,1965$.

[10] C. C. Mundt, "Performance of wheat cultivars and cultivar mixtures in the presence of Cephalosporium stripe," Crop Protection, vol. 21, no. 2, pp. 93-99, 2002.

[11] C. C. Mundt, "Cephalosporium stripe," in Compendium of Wheat Diseases and Pests, W. W. Bockus, R. L. Bowden, R. M. Hunger, W. L. Morrill, T. D. Murray, and R. W. Smiley, Eds., pp. 23-26, APS Press, St. Paul, MN, USA, 3rd edition, 2010.

[12] T. D. Murray, "Seed transmission of Cephalosporium gramineum in winter wheat," Plant Disease, vol. 90, no. 6, pp. 803-806, 2006.

[13] P. Lai and G. W. Bruehl, "Survival of C. gramineum in naturally infested wheat straws in soil in the field and in the laboratory," Phytopathology, vol. 56, pp. 213-218, 1966.

[14] D. E. Mathre and R. H. Johnston, "Cephalosporium stripe of winter wheat: infection processes and host response," Phytopathology, vol. 65, pp. 1244-1249, 1975.

[15] M. V. Wiese and A. V. Ravenscroft, "Quantitative detection of propagules of Cephalosporium gramineum in soil," Phytopathology, vol. 63, pp. 1198-1201, 1973.

[16] D. H. Spalding, G. W. Bruehl, and R. J. Foster, "Possible role of pectinolytic enzymes and polysaccharide in pathogenesis by Cephalosporium gramineum in wheat," Phytopathology, vol. 51, pp. 227-235, 1961.

[17] R. H. Johnston and D. E. Mathre, "Effect of infection by Cephalosporium gramineum on winter wheat," Crop Science, vol. 12, pp. 817-819, 1972.

[18] D. E. Mathre and R. H. Johnston, "Cephalosporium stripe of winter wheat-procedures for determining host response," Crop Science, vol. 15, pp. 591-594, 1975.

[19] J. B. Morton, D. E. Mathre, and R. H. Johnston, "Relation between foliar symptoms and systemic advance of Cephalosporium gramineum during winter wheat development," Phytopathology, vol. 70, pp. 802-807, 1980.

[20] W. W. Bockus, M. A. Davis, and T. C. Todd, "Grain yield responses of winter wheat coinoculated with Cephalosporium gramineum and Gaeumannomyces graminis var. tritici," Plant Disease, vol. 78, no. 1, pp. 11-14, 1994.

[21] D. E. Mathre, R. H. Johnston, and C. F. McGuire, "Cephalosporium stripe of winter wheat-pathogen virulence, sources of resistance, and effect on grain quality," Phytopathology, vol. 67, pp. 1142-1148, 1977.

[22] J. B. Morton and D. E. Mathre, "Physiological-effects of Cephalosporium gramineum on growth and yield of winterwheat cultivars," Phytopathology, vol. 70, pp. 807-811, 1980.

[23] M. J. Richardson and W. J. Rennie, "An estimate of the loss of yield caused by Cephalosporium gramineum in wheat," Plant Pathology, vol. 19, pp. 138-140, 1970.

[24] J. B. Morton and D. E. Mathre, "Identification of resistance to Cephalosporium stripe in winter wheat," Phytopathology, vol. 70, pp. 812-817, 1980.

[25] W. W. Bockus, J. P. O'Connor, and P. J. Raymond, "Effect of residue management method on incidence of Cephalosporium stripe under continuous winter wheat production," Plant Disease, vol. 67, pp. 1323-1324, 1983. 
[26] R. X. Latin, R. W. Harder, and M. V. Wiese, "Incidence of Cephalosporium stripe as influenced by winter wheat management practices," Plant Disease, vol. 66, pp. 229-230, 1982.

[27] J. M. Martin, R. H. Johnston, and D. E. Mathre, "Factors affecting the severity of Cephalosporium stripe of winter wheat," Canadian Journal of Plant Pathology, vol. 11, pp. 361367, 1989.

[28] T. D. Murray, C. C. Walter, and J. C. Anderegg, "Control of Cephalosporium stripe of winter wheat by liming," Plant Disease, vol. 76, pp. 282-286, 1992.

[29] R. A. F. Pool and E. L. Sharp, "Some environmental and cultural factors affecting Cephalosporium stripe of winter wheat," Plant Disease Reporter, vol. 53, pp. 898-902, 1969.

[30] P. J. Raymond and W. W. Bockus, "Effect of seeding date of winter wheat on incidence, severity, and yield loss caused by Cephalosporium stripe in Kansas," Plant Disease, vol. 68, pp. 665-667, 1984.

[31] H. Li, R. L. Conner, and T. D. Murray, "Resistance to soilborne diseases of wheat: contributions from the wheatgrasses Thinopyrum intermedium and Th. ponticum," Canadian Journal of Plant Science, vol. 88, no. 1, pp. 195-205, 2008.

[32] G. W. Bruehl, T. D. Murray, and R. E. Allan, "Resistance of winter wheats to Cephalosporium stripe in the field," Plant Disease, vol. 70, pp. 314-316, 1986.

[33] J. M. Martin, D. E. Mathre, and R. H. Johnston, "Genetic variation for reaction to Cephalosporium gramineum in 4 crosses of winter wheat," Canadian Journal of Plant Science, vol. 63, pp. 623-630, 1983.

[34] P. A. Shefelbine and W. W. Bockus, "Decline of Cephalosporium stripe by monoculture of moderately resistant winter wheat cultivars," Phytopathology, vol. 79, pp. 1127-1131, 1989.

[35] S. Savary, P. S. Teng, L. Willocquet, and F. W. Nutter, "Quantification and modeling of crop losses: a review of purposes," Annual Review of Phytopathology, vol. 44, pp. 89-112, 2006.

[36] C. A. Griffey, M. K. Das, and E. L. Stromberg, "Effectiveness of adult-plant resistance in reducing grain yield loss to powdery mildew in winter wheat," Plant Disease, vol. 77, pp. 618-622, 1993.

[37] S. A. Herrera-Foessel, J. Huerta-Espino, J. Crossa, J. Yuen, and A. Djurle, "Effect of leaf rust on grain yield and yield traits of durum wheats with race-specific and slow-rusting resistance to leaf rust," Plant Disease, vol. 90, no. 8, pp. 1065-1072, 2006.

[38] R. J. Gutteridge, G. L. Bateman, and A. D. Todd, "Variation in the effects of take-all disease on grain yield and quality of winter cereals in field experiments," Pest Management Science, vol. 59, no. 2, pp. 215-224, 2003.

[39] D. E. Roberts and R. E. Allan, "Cephalosporium stripe resistance and grain yield potential of wheat lines with strawbreaker resistance derived from Aegilops ventricosa," Plant Disease, vol. 74, pp. 852-857, 1990.

[40] J. K. M. Brown, "Yield penalties of disease resistance in crops," Current Opinion in Plant Biology, vol. 5, no. 4, pp. 339-344, 2002.

[41] C. B. Purrington, "Costs of resistance," Current Opinion in Plant Biology, vol. 3, no. 4, pp. 305-308, 2000.

[42] J. Bergelson and C. B. Purrington, "Surveying patterns in the cost of resistance in plants," American Naturalist, vol. 148, no. 3, pp. 536-558, 1996. 


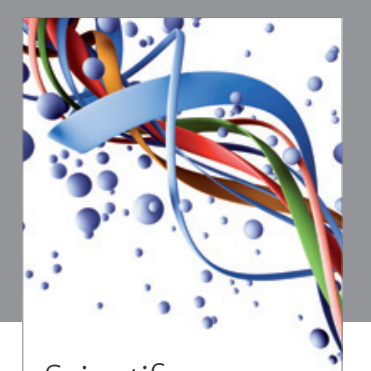

Scientifica
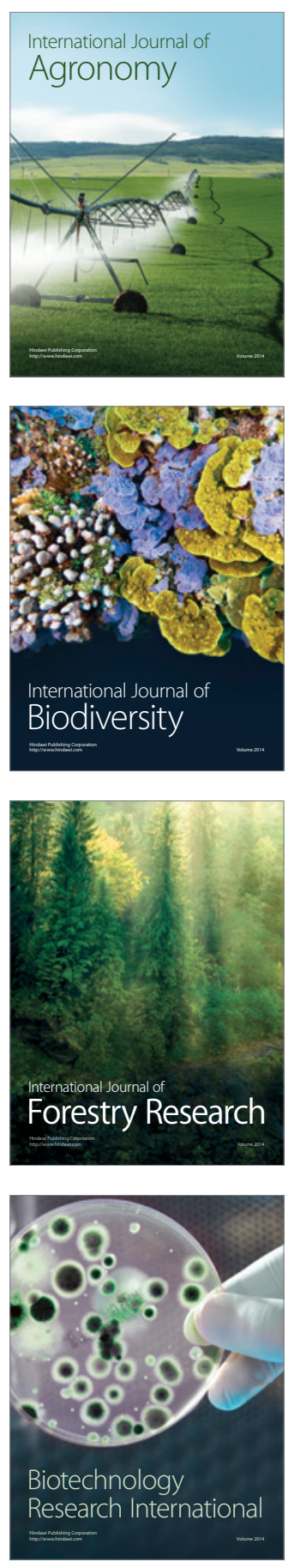
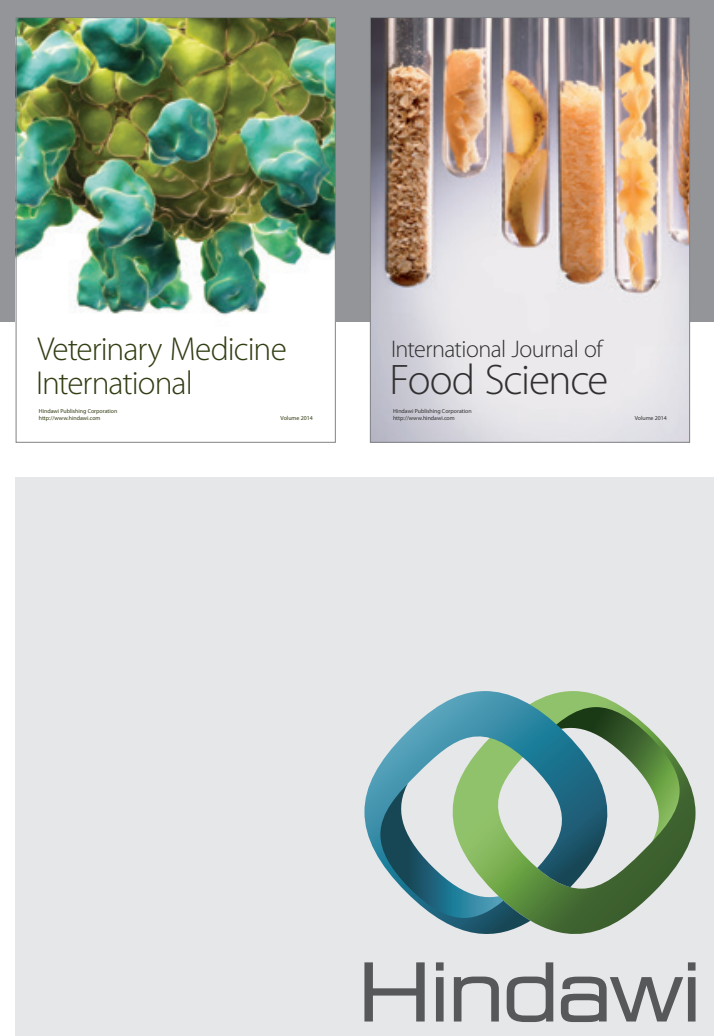

Submit your manuscripts at

http://www.hindawi.com
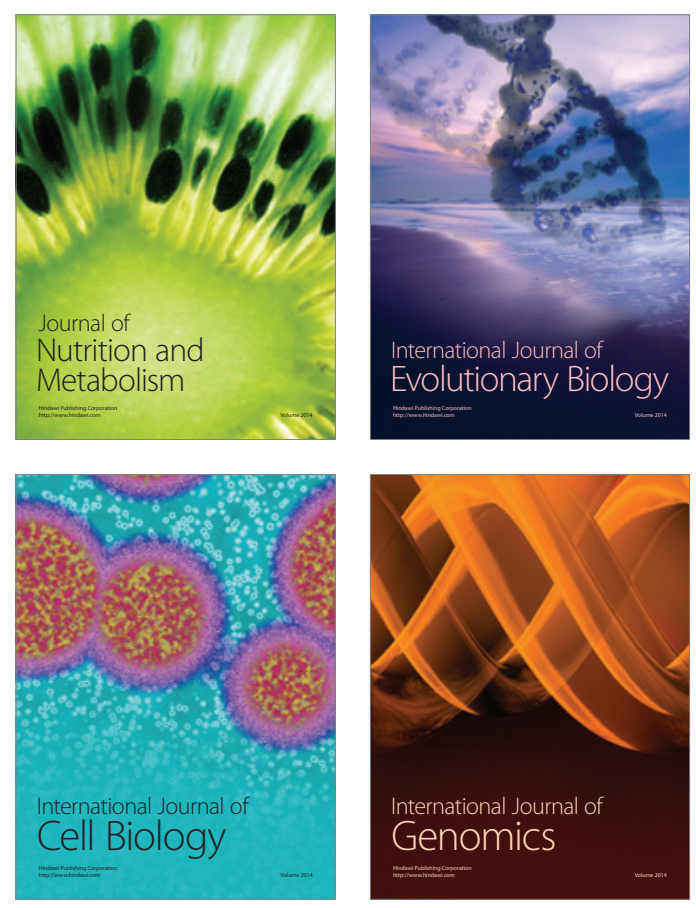
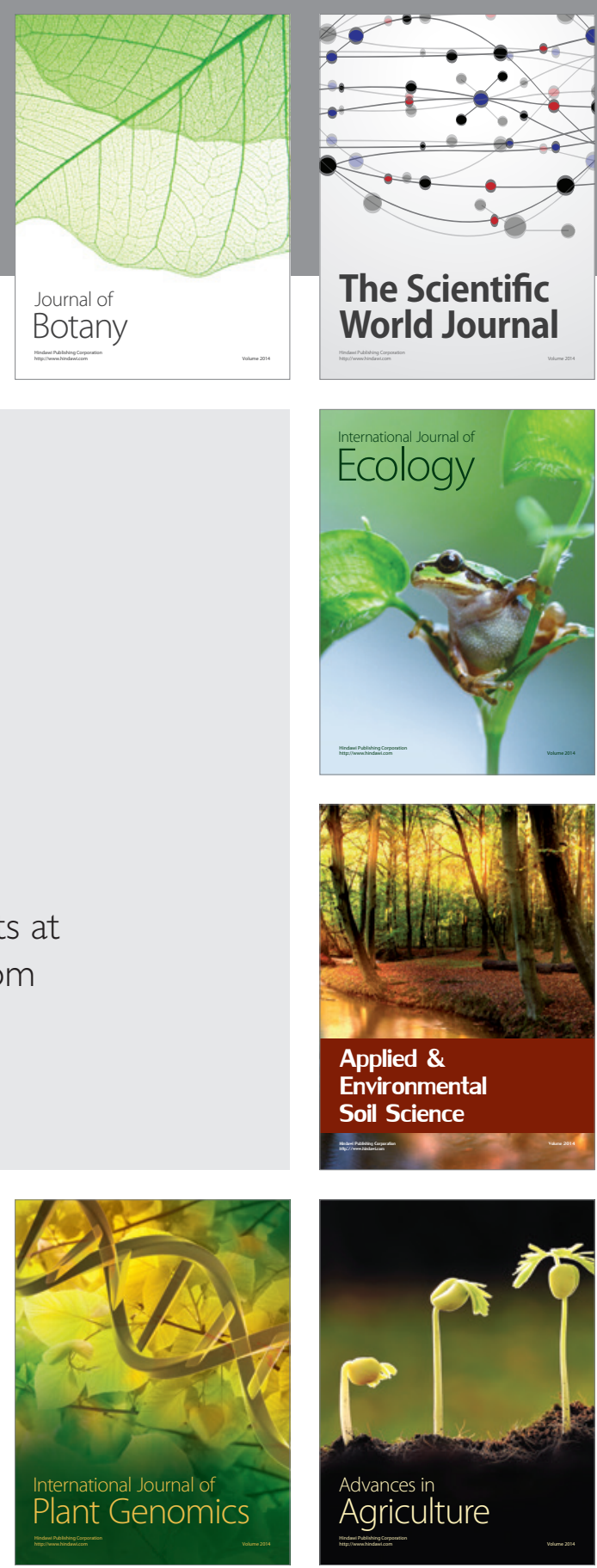

The Scientific World Journal
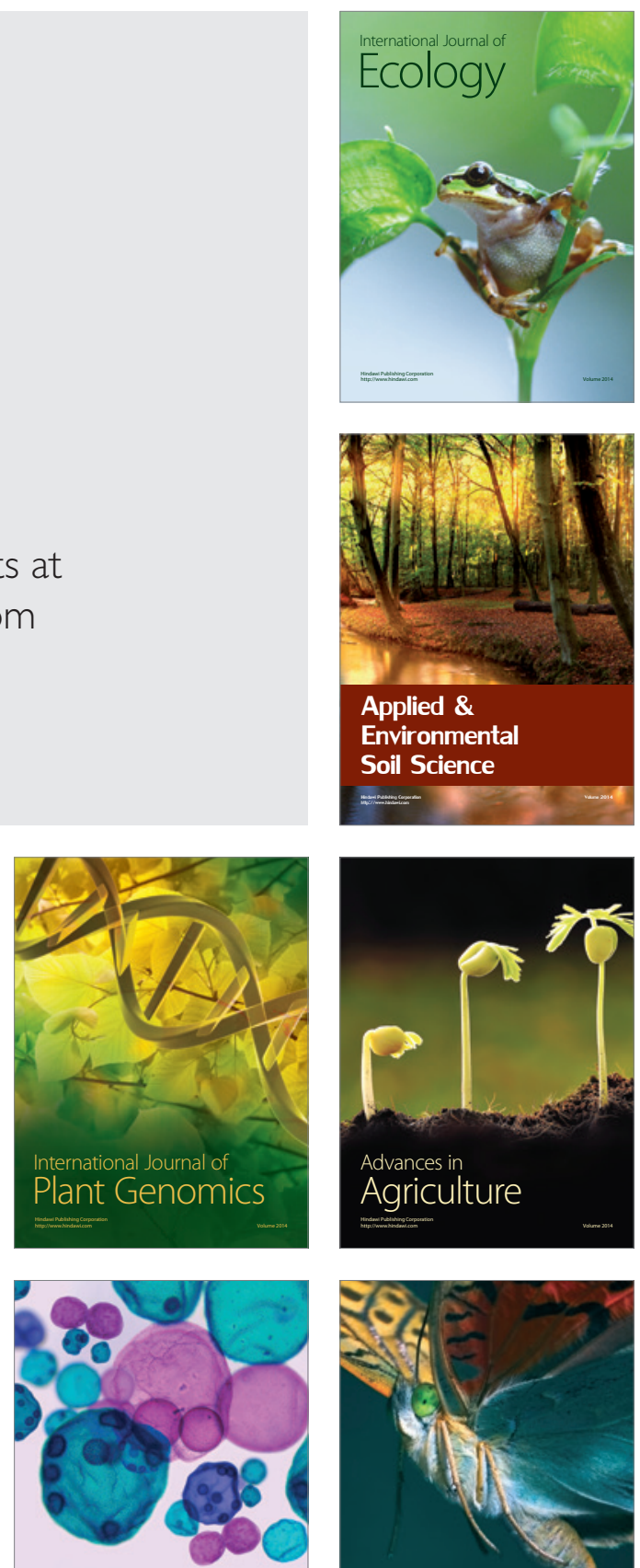

International Journal of Microbiology

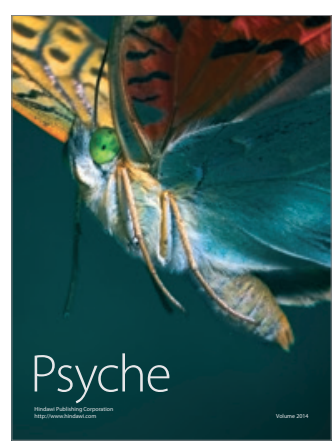

